\title{
Contested Counting: Toward a Rigorous Estimate of the Death Toll in the Rwandan Genocide
}

Omar Shahabudin McDoom

London School of Economics

\section{Address}

Department of Government

Houghton Street, London WC2A 2AE

United Kingdom

Email: o.s.mcdoom@1se.ac.uk

Accepted by the Journal of Genocide Research on June 182019.

As a world-historical event that has become indelibly etched into the conscience of humanity, the Rwandan genocide unequivocally merits scholarly attention to establishing its death toll. The historical record demands it. Preserving the memory of the victims, recognizing the enormity of the crime, and attributing full responsibility to the perpetrators are also compelling reasons to account for the lives taken. Justice also demands it.

Yet in the twenty-five years since the genocide, dramatically divergent claims have emerged in respect of two fundamental aspects of the death toll: the number and the identity of the victims. How many Rwandans were killed? And how many of them were Tutsi, and how many Hutu? If one examines the claims for the overall number killed, at the higher end lies the figure of 1,074,017 Rwandan dead. This number originates with the Rwandan government which conducted a nationwide census in July 2000, six years after the genocide. ${ }^{1}$ Toward the lower end lies an estimate from Human Rights Watch, one of the first organizations on the ground to investigate the genocide, of 507,000 Tutsi killed. ${ }^{2}$

Differences in the claims concerning the victims' ethnic identities are even more stark. In the Rwandan government's census, $93.67 \%$ or just over one million were Tutsi. ${ }^{3}$ In contrast, two

\footnotetext{
${ }^{1}$ Government of Rwanda, Dénombrement Des Victimes Du Genocide: Rapport Final (Kigali: Ministère de L'Administration Locale de L'Information et des Affaires Sociales, 2002). Higher estimates for the death toll exist. For instance, the Student Genocide Survivors' Association (AERG in French) estimated 1,952,078 victims. The Government of Rwanda has not officially endorsed this figure. See https://www.newtimes.co.rw/section/read/5288, accessed 15 June 2019.

2 Alison Des Forges, Leave None to Tell the Story: Genocide in Rwanda (Human Rights Watch; International Federation of Human Rights, 1999), 17.

3 The government's genocide census distinguished "declared" from "enumerated" victims. A victim is enumerated only if the enumerator obtained responses for all questions on the questionnaire. The enumerated figure is slightly lower at 934,218 victims. The report is ambiguous, however, as to whether the $93.67 \%$ refers to the declared or enumerated total. The estimate of over one million Tutsi dead is based on the declared total. If the enumerated total is used, the figure becomes 875,000 Tutsi dead.
} 
contributors to this forum, Davenport and Stam, have in the past contended somewhere between 250,000 and 890,000 Rwandans were killed and suggested - among other possibilities it is possible as few as 50,000 of them were Tutsi and as many as 540,000 of them Hutu. ${ }^{4}$ If their claim that more Hutu were killed than Tutsi is true, this would invite us to revise the common characterization of the violence as a genocide solely against Tutsi. ${ }^{5}$ It implies there may have been a double genocide or additionally a politicide, where individuals were targeted for their political beliefs rather than their ethnic identity.

In this article, I present an estimate of between 491,000 and 522,000 Tutsi killed in the period 6 April to 19 July 1994 within Rwanda. I take care to delimit this estimate both temporally and spatially and to specify it refers only to Tutsi. There have been other periods of major violence in which Rwandans - both Tutsi and Hutu - lost their lives throughout the 1990s and the 2000s. Moreover, some of this violence occurred outside of Rwanda, in the wider Great Lakes region and most notably in the Democratic Republic of Congo. The genocide and its death toll then could be understood in this broader historical and regional context as these other episodes of violence were not unrelated. ${ }^{6}$ Adopting a wider lens, however, should not alter our understanding of the fact that a genocide occurred between April and July 1994 inside Rwanda. ${ }^{7}$ Nor should it lessen the moral responsibility or negate the agency of those who organized and participated in it. The genocide remains a shocking and tragic world-historical event in which the intensity and speed of the violence, and the scale of civilian participation, distinguished it. Nonetheless, situating the genocide and its death toll in this broader context has merit insofar as it serves to underline that the life of every Rwandan taken through such violence deserves to be remembered and accounted for. Memory and justice cannot be selective. ${ }^{8}$

\footnotetext{
${ }^{4}$ Christian Davenport cites a 2010 source jointly-authored with Allan Stam in a 2014 blog entry where these estimates are listed. See http://politicalviolenceataglance.org/2014/10/24/measuring-denying-trivializing-deaths-inthe-case-of-rwanda/, accessed 15 June 2019. In a 2012 Powerpoint presentation, Stam presented a different overall death toll of between 200,000 and 1,250,000 (slide 25) and presented a different possible Tutsi victim count of 206,000 and, as a plausible Bayesian-based estimate, a different possible Hutu victim count of 408,000 (slide 18). The presentation is available on a project website listing Stam and Davenport as the principal investigators. See https://genodynamics.weebly.com/presentations.html, accessed 15 June 2019.

${ }^{5}$ In the BBC documentary Rwanda: The Untold Story (2014), Stam states (at minute 30.33): "If a million people died in Rwanda in 1994, and that's certainly possible, there is no way that the majority of them could be Tutsi."

${ }^{6}$ For an overview of the various episodes of violence in the Great Lakes in the postcolonial era, and the linkages between them, see Omar Shahabudin McDoom, "War and Genocide in Africa's Great Lakes since Independence," in Oxford Handbook of Genocide Studies, ed. Donald Bloxham; A. Dirk Moses (Oxford: Oxford University Press, 2010). ${ }^{7}$ Rwanda's Organic law 08/96 on the Organization of Prosecutions for Offences constituting the Crime of Genocide or Crimes against Humanity defines a genocide victim and sets temporal boundaries from 1 October 1990 to 31 December 1994. While there is scholarly disagreement as to when the genocide was first planned, it is generally recognized that a state-sponsored policy to eliminate all Tutsi was not implemented until almost immediately following president Habyarimana's assassination on 6 April 1994 and ended with the crossing of the interim government and government soldiers into then Zaire and the establishment of a new government by the Rwandan Patriotic Front on 19 July 1994.

${ }^{8}$ This point is powerfully made by Scott Straus, "The Limits of a Genocide Lens: Violence against Rwandans in the 1990s," Journal of Genocide Research 21, no. 4 (2019).
} 


\section{What is it at Stake in Establishing the Genocide's Death Toll}

Both the politics and the emotions surrounding the genocide have provoked and shaped the debate over its death toll. The number and the identities of those killed have become intensely politicized questions in large part because they evidently drive the characterization of the violence. Did the violence targeting Tutsi constitute genocide, the crime of crimes, or something less morally egregious? Should the killing of Hutu be seen as morally less reprehensible or equivalent? The number and identities of the victims then have become weapons in the battles waged between those who would deny, minimize, or equate the genocide with other violence, and those who would insist on its moral uniqueness.

These issues are politicized, however, in part because they are also central in another morally charged debate. They shape our perceptions of who were the victims and the aggressors in the violence. When the asymmetry in the loss of life is stark, the side with the higher civilian casualty count will be more likely viewed as having victim group status; the side that sustained fewer civilian casualties more likely to be seen as the belligerent. Recognition of victim status confers distinct political advantages. It elicits sympathy and induces guilt in those who failed to prevent and stop the violence. Both sentiments may be converted into rhetorical and material support for the victim group. It may also grant the victim group some measure of immunity from criticism as critics risk being compared to the original perpetrators. ${ }^{9}$ In contrast, aggressor status is politically disadvantageous. It erodes legitimacy and casts doubt on claims of selfdefense and any other pretensions of a just cause to the violence. Aggressors must be held to account and punished for their misdeeds. More generally, contestation over victim status functions to reduce the complexity of the violence into the basic binary division between good guys and bad guys; and contestation over the victims' identities latently functions to maintain ethnicity as a politically salient force in society.

The contestation is not, however, driven solely by competing political logics and strategies. Discussion of genocide also evokes powerful emotions. It stirs feelings of anger, grievance, guilt, remorse, and even fear. Affect, as social psychologists have long established, biases judgements and evaluations. ${ }^{10}$ Emotions, alongside politics, then represent another force that distorts and obfuscates the true death toll. Disputes over the number and identity of the

\footnotetext{
9 See Filip Reyntjens, "Rwanda, Ten Years On: From Genocide to Dictatorship," African Affairs 103 (2004): 177-210, where he argues the post-genocide Rwandan government skilfully exploited a "genocide credit" to silence criticism of itself.

10 See Dacher Keltner and Jennifer S Lerner, "Emotion," in Handbook of Social Psychology, ed. Susan Fiske, Daniel Gilbert, and Gardner Lindzey (New Jersey: John Wiley \& Sons, 2010), 317-352.
} 
victims in genocides should be anticipated. Scholars would do well then to set clear standards for evaluating the competing claims that they know will be made. I begin then by proposing some criteria I believe should be considered when generating, and also evaluating, estimates for the victims of genocide. These guidelines should certainly not be seen as the definitive word on the subject. Rather, they should be considered part of an evolving conversation. Better criteria will be developed in time.

\section{Towards Some Guidelines for Establishing Genocide Death Tolls}

First, as already suggested, the violence whose toll we are seeking to establish should itself be carefully delimited. At a basic level this requires setting temporal and spatial boundaries. The more complex challenge are the conceptual boundaries. Multiple violent events may occur within the same temporal and spatial limits but these events may comprise conceptually distinct forms of violence. In Rwanda, a genocide against Tutsi unambiguously occurred between 6 April and 19 July 1994. However, other types of violence also took place: the assassinations of moderate Hutu and Tutsi political elites; retributive killings of Hutu civilians by the RPF; personal scoresettling among ordinary Rwandans; and combatant deaths on both sides of a civil war. Conceptually subsuming all this violence within the label genocide not only reduces important complexity; it weakens the recognition of these other lives lost.

Second, there should be a degree of transparency in the data and methods sufficient to be able to replicate and verify the estimate. The methodological assumptions and choices should be set out and the data relied upon made available upon request. Third, a reasoned judgement on the reliability of the data chosen and the suitability of the method selected should be offered. As a basic standard, the author of the estimate should explain why they opted for their particular data and, insofar as they are independent of the data, their methods too. If the data were chosen because no alternatives were available to the author, this should be made clear. As a higher standard, and a more complex task, the author should offer a judgement on the potential biases in a data source. Competing data sources should not be presented as equally reliable if there is reason to believe bias may exist. Establishing estimates should not be simply a matter of calculating an average across data sources. This rewards biased outliers.

Finally, the author should endeavour to situate their claim among the better-known estimates already published to help the reader gauge how close it is to these others. Consensusbuilding is an important part of the process of establishing the historical record.

\section{Methods and Data}


Generally, two methods are commonly followed in establishing the genocide's death toll: counting the dead or counting the survivors. Notwithstanding the method chosen, the reliability of all estimates depends on two crucial numbers: the number of Tutsi in Rwanda on the eve of the genocide; and the number of Tutsi who survived the genocide.

\section{How Many Tutsi Lived in Rwanda Before the Genocide?}

According to the 1978 and 1991 population censuses, there were 467,587 and 597,459 Tutsi resident in Rwanda respectively at the time they were conducted. Tutsi then represented $9.8 \%$ and $8.4 \%$ of the population. ${ }^{11}$ If we extrapolate from these figures to April 1994 using the historical average population growth rate specific to each of Rwanda's eleven administrative prefectures, this would mean there were between 714,000 and 647,000 Tutsi in Rwanda just before the genocide. However, it has been claimed that both censuses significantly underestimated the Tutsi population. ${ }^{12}$ Two reasons are usually given. First, the Habyarimana government (1973-1994) may have purposely understated the Tutsi population in order to justify ethnic quotas it had introduced in the 1970s to reverse the longstanding over-representation of Tutsi in educational institutions and the civil service. Second, some Tutsi may have identified themselves as Hutu to census enumerators to avoid state-sponsored discrimination during the Habyarimana era.

At first glance, the colonial census data appear to support the contention that the two postcolonial censuses underestimated the Tutsi population. Tutsi represented $16.7 \%, 17.5 \%$, and $16.6 \%$ in the 1933, 1952, and 1956 censuses respectively. ${ }^{13}$ However, a good part of the difference between the colonial and postcolonial periods is explained by the exodus of tens of thousands of Tutsi during and soon after the Hutu revolution (1959-62) that ushered in Rwanda's independence. A 1964 UNHCR census estimated 336,000 refugees, mainly Tutsi, had fled to Burundi, Uganda, Zaire, and Tanzania. ${ }^{14}$ Rwanda's population stood at 2,634,000 in 1959

\footnotetext{
11 See Government of Rwanda, Récensement Général De La Population Et De L'babitat: Résultats Définitifs (Kigali: Bureau National de Récensement, 1978); Récensement Général De La Population Et De L'babitat Au Août 1991: Résultats Définitifs (Kigali: Ministère du Plan, 1994). The Tutsi proportion is calculated as a percentage of the population of Rwandan citizens only. If non-Rwandans were included, the proportions would drop slightly to $9.7 \%$ and $8.3 \%$ for 1978 and 1991 respectively.

12 See for example Gérard Prunier, The Rwanda Crisis, 1959-1994 : History of a Genocide (London: Hurst and Company, 1995), 264.

13 For the 1933 data, see Mahmood Mamdani, When Victims Become Killers : Colonialism, Nativism and the Genocide in Rwanda (Oxford: James Currey, 2001), 98. For the 1952 data, see Des Forges, Leave None to Tell the Story : Genocide in Rwanda, 40. For the 1956 data, Filip Reyntjens, Pouvoir Et Droit Au Rwanda: Droit Public Et Évolution Politique, 19161973 (Tervuren: Musée Royal de l'Afrique Centrale, 1985), 28.

${ }^{14}$ Cited in André Guichaoua, Le Problème Des Réfugiés Rwandais Et Des Populations Banyarwanda Dans La Région Des Grands Lacs Africains (Geneva: United Nations High Commission for Refugees, 1992), 20.
} 
which would mean, at most, 461,000 Tutsi (17.5\%) were resident in Rwanda prior to the revolution. ${ }^{15}$ If the UNHCR census is accurate, projecting forward to 1994 would mean there would have been only some 350,000 Tutsi in Rwanda on the eve of the genocide. As the national census, already believed to be an underestimate, puts the Tutsi population at 597,000 in August 1991, this figure is implausibly low. Either the UNHCR data are unreliable, the 1959 population data are inaccurate, or else tens of thousands Hutu also went into exile with Tutsi. Whatever the reason, it appears dependence on the colonial-era data, which may have been reliable, to estimate the postcolonial Tutsi population depends on other data whose reliability is more questionable.

An alternative method for establishing the Tutsi baseline pre-genocide would be to examine locally-collected administrative population data. These local data offer two advantages over the national census data. First, they were collected more frequently, often several times per year, allowing us to observe any unusual changes in the trend. Second, individuals were less likely to be able to misrepresent their ethnicity. Before the genocide, each of Rwanda's 145 administrative communes maintained registers of births, deaths, and migrations based on information provided either by the administrative cell heads (responsables) or else by the heads of blocks of ten households (nyumbakumi). These local administrative figures, who lived within the community, typically knew members personally and it would have been very difficult for a Tutsi family to pretend it was Hutu. The data in these commune registers were then used by each of Rwanda's eleven prefectures to produce annual administrative census reports.

How reliable are these local censuses? Local data collection capacity may well vary between localities and over time. I analysed the reported data in two localities and over 8 distinct time periods to probe their reliability. During fieldwork in 2003 I found in prefecture archives the original population reports for 1965, 1975, 1983, 1985, and 1988 for Butare prefecture, in which Tutsi represented $18.3 \%, 18.5 \%, 18.3 \%, 18.3 \%$, and $17.8 \%$ respectively. I also found the reports from 1965, 1973, 1981, 1985, 1988, and 1991 for Ruhengeri prefecture in which Tutsi represented $0.8 \%, 0.7 \%, 0.7 \%, 0.7 \%, 0.6 \%$, and $0.6 \%$ of the population respectively. The proportion of Tutsi reported in the local administrative data then remained reasonably stable over twenty-five years. Importantly, the first reports, from 1965, predate the introduction of Habyarimana's ethnic quotas in the 1970s when the ethnic balance would have become politicized. The trend in the local data then does not suggest any sudden, large, or otherwise suspicious shift in the Tutsi proportion. The observed gradual decline over time likely reflects

\footnotetext{
15 The 1959 population estimate comes from Office de l'Information et des Relations Publiques pour le Congo Belge et le Ruanda-Urundi, (1959), 33, cited in Reyntjens, Pouvoir Et Droit Au Rwanda: Droit Public Et Évolution Politique, 1916-1973, 21.
} 
the lower Tutsi female fertility rate. ${ }^{16}$ At least as an indicator of the Tutsi proportion, the local administrative data then appear reasonably reliable.

\section{Did the 1991 National Census Underestimate the Tutsi Population?}

I compared the national census data against the local data I had for Ruhengeri prefecture for 31 December 1991, adjusted to 15-16 August 1991, the national census reference date. To ensure data comparability, I counted only Rwandan citizens who were resident and physically present in their household on the census reference date. Two main findings emerge. First, the overall population matched reasonably well. The national census put Ruhengeri's population at 741,705; the date-adjusted local census data predicted a population of 734,697 . The difference, $0.95 \%$, is not inconsequential, though some of the difference may be attributable to the adjustment using the average historical population growth rate (3.1\% p.a. for Ruhengeri) or simply lower administrative capacity and efficiency at the local level. Second, and more interestingly, the national census reported the Hutu population higher and the Tutsi and Twa population significantly lower than in the local data. In relative terms, the Hutu population was overstated by $1.07 \%$ and the Tutsi and Twa understated by $14.48 \%$ and $9.20 \%$ respectively. Insofar as Ruhengeri prefecture was not exceptional, it does appear then the national census did undercount the Tutsi.

Was this undercounting the result of deliberate central manipulation of the data or individuals mispresenting their ethnicity to census enumerators? The data do not permit a conclusive answer. However, it is worth noting that the number of ethnic Twa were undercounted as well as the number of Tutsi. If the rationale for central manipulation was to reverse Tutsi over-representation in educational establishments and the civil service, this would suggest the cause was local self-identification as Hutu rather than central government manipulation. The Twa were a historically marginalized group and were likely under-represented in the public sector and education. Both Tutsi and Twa had incentives to identify as Hutu because of the advantageous status it afforded.

\section{Establishing the Tutsi Pre-Genocide Baseline}

Given the stability over time in the population share of Tutsi in the local administrative data, they represent a potentially valuable alternative source to the national census for estimating the pre-genocide Tutsi population. The only year for which I had administrative population data for

\footnotetext{
${ }_{16}$ Using data from the Rwanda Demographic and Health Survey for 1991, I calculated Hutu women had on average 6.2 children in their lifetime, whereas Tutsi women had only 5.1 .
} 
all eleven prefectures was $1983 .{ }^{17}$ In 1983, the national proportion (excluding foreigners) of Tutsi was $10.8 \%$. It is worth noting that the Tutsi proportions for Butare and Ruhengeri prefectures were $18.34 \%$ and $0.66 \%$, in line with the other administrative censuses going back to 1965 . The administrative data for 1983 then did not appear unusual. If we assume the 1991 national census correctly stated Rwanda's overall population, and only misstated the ethnic balance between Hutu, Tutsi, and Twa, then if we extrapolate the census data forward from August $15^{\text {th }} 1991$ to April 6 1994 (966 days) using the national annual population growth rate of 3.1\%, Rwanda's overall population on the eve of the genocide would have been approximately 7,415,000 persons. ${ }^{18}$ This figure refers to Rwandan citizens who were resident and present in their usual household on the census reference date. ${ }^{19}$ If the Tutsi population were $10.8 \%$ of this figure, I estimate roughly 800,000 Tutsi were living within Rwanda on the eve of the genocide.

\section{How Many Tutsi Survivors Were There?}

To my knowledge, there have been two widely-cited but significantly different survivor estimates. The first estimate of 150,000 is the aggregation of three other estimates: (i) an anonymous international civil servant's estimate of Tutsi living in refugee camps in July 1994 $(105,000)$; (ii) an unsupported estimate of 25,000 Tutsi inside Rwanda who did not go to the camps; and (iii) another unsupported estimate of 20,000 Tutsi who escaped to Tanzania and Zaire. ${ }^{20}$ The second estimate of 309,000 is based on a 2006 national census, conducted by the National Institute of Statistics of Rwanda (NISR), a Rwandan governmental body. ${ }^{21}$ It asked the local heads (responsables) of Rwanda's smallest administrative unit, the imidugudu, to enumerate the survivor households in their communities. To these two well-known estimates, I add a third estimate of 202,000 based on the Rwandan government's gacaca data. Rwanda's gacaca courts were an innovative community justice institution established by the government with the stated aims of holding to account local perpetrators, establishing the truth of what transpired in those communities, and assisting in reconciliation. Local communities compiled extensive information

\footnotetext{
${ }_{17}$ The 1983 administrative data were summarized and submitted in May 2005 as exhibit 2D49 in the trial of Bizimungu et al., ICTR-99-50-T. The data were compiled for the Defense by expert witness, Rwandan anthropologist, Professor Deo Mbonyinkebe.

18 The annual national population growth rate of 3.1\% is calculated for the period 1978-1991. See Government of Rwanda, Récensement Général De La Population Et De L'habitat Au Août 1991: Résultats Définitifs, 13.

${ }^{19}$ I consider only Rwandans who were present on the census reference night of August $15^{\text {th }} 1991$ in order to ensure comparability with the 1983 administrative data. The summary of the administrative census data in my possession reported only the population of Hutu, Tutsi, and Twa. Non-Rwandans were not reported. Administrative censuses also generally reported only present individuals. Individuals temporarily absent (away for less than 6 months) were not reported. If both Rwandan and non-Rwandans, and both individuals present and absent on the census reference night were counted, the overall population of Rwanda on 6 April 1994 would have been approximately 7,761,000.

20 See Prunier, The Rwanda Crisis, 1959-1994, 264; Des Forges, Leave None to Tell the Story, 17.

${ }^{21}$ See Government of Rwanda, Récensement Des Rescapés Du Genocide De 1994: Rapport Final (Kigali: Institut National de la Statistique du Rwanda, 2008).
} 
on the genocide as part of gacaca and the Rwandan government published a summary of some of these data in $2007 .^{22}$ They included the number of survivors in local communities.

My assessment of the reliability of each estimate is varied. The first estimate of 150,000, although the most longstanding, has the least well-documented empirical basis to it. Two of the three estimates on which it depends - essentially the number of Tutsi outside of the refugee camps - appear to be educated guesses with no evidence offered to support them. I must regard it then as the least reliable. This leaves the two government estimates between which the difference, 107,000 , is still very large. I had field data that allowed me to ground-truth the accuracy of the smaller, gacaca estimate of 202,000 survivors. Specifically, I had data on the number of Tutsi resident and the number of Tutsi killed in 20 administrative sectors in Ruhengeri and Butare prefectures that had been part of the initial gacaca pilot exercise. Importantly, I had collected these data in 2003 directly from the pilot communities themselves before the data had been passed to the national-level authorities charged with their compilation. These data were based on handwritten lists drawn up by the community enumerating the entire sector population and also those killed by name. I viewed them as reliable. I could calculate with confidence how many Tutsi survived in these particular 20 sectors. Comparing these numbers against the 2007 national gacaca data, however, shows almost no correspondence. For 10 sectors, the national gacaca data understated the number of survivors by an average of $19.6 \%$. For the other 10 sectors, the national data more troublingly overstated the number by an average of $48.6 \%$. I conclude then that the 2007 national gacaca estimate of 202,000 survivors is also unreliable.

This leaves the reliability of the 2006 survivor census of 309,000 individuals to assess. Government estimates will inevitably be vulnerable to the charge of manipulation for political purposes. In this instance, however, there may have been little incentive to inflate the figure. The survivor census was not undertaken by the FARG, the government agency charged with assisting survivors and whose budget would depend on their number. It was conducted by the formally independent Rwandan statistics agency. A very high survivor number would also call into question the government's claim of one million Tutsi dead, a number that has greater political importance for it. In my view, the risk that the survivor data had been exaggerated for political purposes was small. The main concern with this figure, however, is its definition of a survivor. The census uses an expansive definition: "Any person pursued for his ethnic affiliation, his ideology, or that of a family member, against divisionism, exclusionism, or extermination, and

\footnotetext{
22 The Rwandan government's webpage on which the gacaca summary report was released is no longer active. However, Marijke Verpoorten, one of the contributors to this forum, downloaded the report before it went offline and entered the data electronically. She generously shared the dataset with me.
} 
who escaped massacres and genocides committed between October 11990 and December 31 1994." ${ }^{23}$ Survivors then could include individuals killed before April 1994 and also persons who were not Tutsi. One of the most important groups subsumed within this broad definition were the Hutu widows and widowers of Tutsi partners. The census enumerated 31,776 widows and widowers, $10.3 \%$ of all survivors. It did not, however, distinguish their ethnicity. If we assume, albeit an unlikely possibility, all of them were Hutu, the lower bound for the number of Tutsi survivors would become 277,592. My best overall estimate for the number of Tutsi genocide survivors then is between 278,000 and 309,000 individuals.

\section{How many Tutsi were killed during the genocide?}

Subtracting the best estimate of the number of survivors from the best estimate of the pre-genocide Tutsi population, I believe the number of Tutsi killed during the genocide lies between 491,000 and 522,000 individuals. If accurate, then nearly two-thirds of Rwanda's Tutsi population were exterminated between April and July 1994. The finding should leave little doubt as to whether the violence amounted to genocide.

\section{How Many Hutu were Killed During the Genocide?}

Establishing the number of Hutu killed during the genocide matters for three key reasons: it shapes the characterization of the violence; it raises questions of the experience of memory and justice following the genocide; and, by extension, it has implications for the possibilities of interethnic reconciliation. The number has been central then to debates over whether the violence amounted to a double genocide or a politicide; whether Rwanda has experienced victor's justice and institutionalized an asymmetric public commemoration of the victims; and whether the country has successfully escaped the risk of renewed ethnic violence.

I do not have new data to improve upon the estimates already in the public domain for the number of Hutu killed during the genocide period. Scholarly attention has focused in particular on Hutu civilians killed by rebel forces, the Rwandan Patriotic Army (RPA), as they advanced and captured territory. Two of the more widely-cited estimates, by the late Alison Des Forges of Human Rights Watch, and Robert Gersony, a UN consultant who conducted a field investigation in 1994 but whose report was not officially released, put the figure at between 25,000-30,000 and 25,000 - 45,000 respectively. ${ }^{24}$ These estimates should be seen as a lower

\footnotetext{
23 Government of Rwanda, Récensement Des Rescapés Du Genocide De 1994, 3. Author's translation from French.

${ }^{24}$ For both estimates, see Des Forges, Leave None to Tell the Story, 17 \& 558.
} 
bound. Gersony visited only 41 of 145 communes inside Rwanda. Davenport and Stam have also estimated as many as 80,000 persons may have been killed in RPF-controlled areas. ${ }^{25}$ There is also evidence of Hutu killed for other reasons in this time period: the assassinations of political moderates; combatant deaths between two armed groups; interpersonal disputes, often landrelated, between ordinary Rwandans; and the targeting of individuals considered sympathetic to Tutsi. We have little systematic evidence of these deaths. Verwimp conducted a survey that included 1620 Hutu across three Rwandan prefectures. He found forty-three Hutu (2.7\%) suffered violent deaths of whom twenty-one were killed by the RPA, nine by Hutu militia, one by Rwandan government soldiers, five by other, unspecified individuals, and eight by authors unknown. In general, however, the deaths of all these non-Tutsi Rwandans in this time period remain poorly documented and estimates will unlikely improve much until investigations with a view to a judicial accounting for them are initiated. The current and limited evidence we do have of Hutu civilian deaths in this time period does not, in my view, support claims of a double genocide or a politicide. It also does not challenge the evidence that a genocide against Tutsi took place. It does serve to underscore, however, that forms of violence other than genocide occurred at the same time in Rwanda for which there has been limited recognition. The exclusive focus on the genocide unfortunately obscures this other violence.

I have purposely limited discussion of the Hutu death toll to the period 6 April to 19 July 1994, and to violence within Rwanda, as this is generally recognized as the time, and place, in which the Rwandan genocide occurred. The estimate I offered for the Tutsi death toll equally relates to this time period and to events inside Rwanda. However, it would be remiss not to consider how the death toll would change if these particular temporal and spatial boundaries were drawn differently. There have been major episodes of violence claiming the lives of nonTutsi Rwandans both before and after the genocide, and both inside and outside of Rwanda. These events did not occur independently of each other, at least not in the minds of the parties involved in them. Straus has proposed a useful periodization of this violence, along with possible death tolls. ${ }^{26}$ Six time periods are distinguishable: (i) the civil war leading up to president Habyarimana's assassination (October 1990 to April 1994); (ii) the genocide itself (April to July 1994); (iii) the consolidation of power by the RPF (August 1994-1995); (iv) the pursuit of Hutu refugees in the D.R.C. (1996-97); (v) the insurgency and counterinsurgency in Rwanda's northwest (1997-98); and (vi) authoritarian repression inside Rwanda (2000 onwards). Aggregating the various estimates offered for these episodes, excluding the genocide, places the death toll of non-

\footnotetext{
${ }^{25}$ See Christian Davenport and Allan Stam, "Rwandan Political Violence in Space and Time" (Unpublished manuscript). Available at https://genodynamics.weebly.com/writings.html, accessed 17 June 2019.

26 See Straus, "The Limits of a Genocide Lens: Violence against Rwandans in the 1990s," 7-12.
} 
Tutsi Rwandans in the several hundreds of thousands. The most significant of these is the systematic targeting of Hutu refugees in the D.R.C., for which the strongest claim of a second genocide has been made. ${ }^{27}$ In comparison with the genocide against the Tutsi, all these episodes have received far less recognition; the estimates of their death tolls are much more imprecise; and, most troublingly, accountability for them has been woefully limited.

\section{Conclusion}

I have estimated between 491,000 and 522,000 Tutsi, nearly two thirds of Rwanda's pre-genocide Tutsi population, were killed between 6 April and 19 July 1994. I calculated this death toll by subtracting my estimate of between 278,000 and 309,000 Tutsi survivors from my estimate of a baseline Tutsi population of almost exactly 800,000 , or $10.8 \%$ of the overall population, on the eve of the genocide. My estimate is in line with Human Rights Watch's (HRW) early estimate of 507,000, though HRW relied on the 1991 national census to estimate a pre-genocide Tutsi population of 657,000 and assumed there were 150,000 survivors. It is somewhat lower than Verpoorten's figures of 512,000 to 662,000 Tutsi dead, who estimated a pre-genocide Tutsi population of 812,000 , using the 1987 administrative census data where Tutsi represented $10.6 \%$ of the population, and that the number of survivors lay between 150,000 and $300,000 .{ }^{28} \mathrm{My}$ estimate is also lower than Prunier's figure of 800,000-850,000, who assumed Tutsi represented $12 \%$ of the population and that only 130,000 Tutsi survived. ${ }^{29}$

In comparison with estimates at the higher and lower ends, my estimate is significantly lower than the Government of Rwanda's genocide census figure of 1,006,031 Tutsi killed. I believe this number is not credible. If added to the government's own survivor census of 309,000 persons (assuming all were Tutsi), it would require the Tutsi to have constituted 1.3 million or $17.8 \%$ of Rwanda's pre-genocide population, a proportion slightly higher than that in the colonial era. This in turn would imply the exodus of (mainly) Tutsi during and after Rwanda's revolution (1959-62) did not take place and would leave the size of the Tutsi refugee

\footnotetext{
${ }^{27}$ The United Nations High Commission for Human Rights, Report of the Mapping Exercise Documenting the Most Serious Violations of Human Rights and International Humanitarian Law Committed within the Territory of the Democratic Republic of the Congo between March 1993 and June 2003 (2010), presents the results of the most serious investigation into the violence in the D.R.C. in this time period so far. The report does not conclude whether the violence qualified as genocide, stating this requires a judicial determination, but does state in paragraph 31 several incidents occurred "...from which a court could infer the intention to destroy the Hutu ethnic group in the DRC in part..." In Straus, "The Limits of a Genocide Lens: Violence against Rwandans in the 1990s," 11, a stronger assessment is offered: "In my view, of the four episodes of violence described in this essay, the sustained, large-scale violence against the Rwandan Hutu population in the Democratic Republic of Congo is the one that could warrant the label of "genocide." ${ }^{28}$ Verpoorten's estimate and detailed explanation of how she derived it may be found in an online opinion piece at https://africanarguments.org/2014/10/27/rwanda-why-davenport-and-stams-calculation-that-200000-tutsi-died-inthe-genocide-is-wrong-by-marijke-verpoorten/, accessed 15 June 2019.

29 Prunier, The Rwanda Crisis, 1959-1994, 265.
} 
population before the genocide unexplained. In contrast, my estimate is significantly higher than Davenport and Stam's estimate of between 206,000 to 376,000 Tutsi killed. While they believe the number of survivors lies between 130,000 and 300,000 as several others do, they rely on a much lower pre-genocide Tutsi population of 506,000. ${ }^{30}$ This figure is extrapolated from the 1952 colonial census, taking into account UNHCR data on refugees from the revolution, and using a population growth rate of $2.5 \%$ per annum up until 1990 when the war begins. The figure of 506,000 Tutsi in Rwanda in April 1994, however, is dubious. It is sensitive to the UNHCR estimates of the number of Rwandan refugees in the region, and to the assumed population growth rate. The reliability of the UNHCR data has already been investigated and questioned given dramatic fluctuations in the figures over time that remain unexplained. ${ }^{31}$ It is also significantly lower than the Rwandan national census' figure which puts the number at 597,000 in August 1991 or 645,000 in April 1994. These figures are themselves already widelyseen as an under-estimate.

Genocide is an intrinsically exclusionary concept. The desire to reserve the unique moral and abhorrent nature of the term genocide for the victim group, and to resist claims by others who suffered violence also to be recognized as genocide victims, is powerful. The Rwandan government's decision to specify in the constitution the genocide was specifically against the Tutsi exemplifies this exclusionary and proprietary urge. The several estimates for the death toll offered in this forum, however, should leave little doubt that a genocide targeting Tutsi occurred. The investment of significant scholarly resources into establishing the genocide's toll is a worthwhile exercise both for the production of a historical record and for reasons of memory, justice, and accountability. However, the violence that claimed Rwandan lives in the 1990s was varied and complex. Other forms of violence took place in Rwanda at the same time as the genocide. Other forms of violence also preceded and followed the genocide, both inside and outside of Rwanda, that are linked to it, at least in the minds of those who were its targets. In setting a future research agenda, scholars should consider the value of committing resources to

\footnotetext{
30 The survivor figures of 130,000-300,000 are cited in Davenport and Stam, "Rwandan Political Violence in Space and Time." The pre-genocide Tutsi population estimate of 506,000 is cited on their project website in a Powerpoint presentation Stam made in 2012 (slide 18). https://genodynamics.weebly.com/presentations.html, accessed 15 June 2019. In the BBC documentary Rwanda's Untold Story, Davenport and Stam are interviewed and Stam repeats the estimate that 200,000 Tutsi may have been killed (at minute 31.05) and the narrator also repeats their estimate of a pre-genocide Tutsi population of 500,000. However, in an online magazine article, Davenport and Stam cite a different Tutsi death toll of 300,000-500,000 based on a different pre-genocide Tutsi population extrapolated from the 1991 national census. See https://psmag.com/social-justice/what-really-happened-in-rwanda-3432, accessed 17 June 2019.

${ }_{31}$ See Guichaoua, Le Problème Des Réfugiés Rwandais Et Des Populations Banyarwanda Dans La Région Des Grands Lacs Africains, 20-24.
} 
documenting the victims of these other kinds of violence. They too deserve to be remembered, and they too deserve justice. 